\title{
SEXUAL DEVIANCE. THE SEXUAL SADISM
}

\author{
LARISA-MARIA COSTRACHEVICI ${ }^{1 *}$, CRISTIAN DELCEA ${ }^{1,2}$ \\ 1/uliu Hațieganu University of Medicine and Pharmacy, Cluj-Napoca, Romania \\ 2Sexology Institute of Romania, Cluj-Napoca, Romania
}

\begin{abstract}
Sexual deviance is in some way a socially constructed phenomenon that shifts over time with public opinion. The various forms of sexual deviancy are grouped and defined utilizing the DSM-IV descriptions (American Psychitric Association, 1994), because this clasification it is the most frequently used in forensic settings. Adult sexual assault is an essential focus of forensic psychology, variously diagnosed as sexual sadism, paraphilia NOS (not otherwise specified), or undiagnosed. Other forms of sexual deviance presented here include voyeurism, exhibitionism, frotteurism, sexual sadism, rape and pedophilia. Each category is briefly explored through its etiology, course, epidemiology, assessment and treatment (Sbraga, 2004). Sexual sadism is said to be a disorder in which sexual satisfaction is reached and causing another suffering, psysical or mental pain through humiliation. In this article, its about addressing some theoretical aspects regarding the sexual deviance, but also the exemplification of a parafilic category, namely sexual sadism.
\end{abstract}

Keywords: sexual deviance, sadism, parafilic category, sexual behaviour.

\section{INTRODUCTION}

The concept of sexual deviance refers to the nature of sexual behavior that is nonconforming whit expectations or societal norms, is of maladaptive nature and interferes with the individual functioning (Laws and $\mathrm{O}^{\prime}$ Donohue, 1997; Paulauskas, 2012). Sexually deviant behaviors are identified by one or more of the following standards: degree of consenst, the nature of the person or object involved in the action, the actual action and body parts that are utilized, the setting in which the bahavior is performed. In clinical literature sexual deviance is referred to as Paraphilia and manifests itself as a disorder characterized by recurrent, intense sexually arousing fantasies, sexual urges or behaviors involving nonhuman objects, suffering and humiliation of oneself or one's partner, children and other nonconsenting persons. A period of six months last these fantasies, bahaviors or urges, and they cause distress or interpersonal difficulties (DSM -IV - TR, 2000; Paulauskas, 2013).

Sexual deviance encompasses a wide spectrum of sexually aberrant behaviors and ranges from exhibitionism, fetishism, voyeurism, pedophilia, to incest and sadistic rape at the extreme end. Many researchers, clinicians and law enforcement representatives consider this behaviors as a major mental health and criminal justice problem. Other terms related to sexual deviance include: sexually abnormal behavior, sexual perversion, sexual assault, and sexual offending; however, their meanings are not identical and the terms are often used in different contexts (Paulauskas, 2013).

*Corresponding author: 160 Plevnei Street, Cluj-Napoca, 400000, Romania, Phone/Fax: 0264 550247, email cristian.delcea.cj@gmail.com 
According to the classification made by J. Gagnon and W. Simon (1967), there are three types of sexual deviance, depending on the magnitude of the deviation and the degree of tolerance manifested by the community.

Normal sexual deviance, including behaviors, acts or preferences characterized by a low correspondence between social rules, legal prescriptions and the behaviors of individuals (the case of masturbation, pre-marital sexual relations, oral sex, etc.), practices that have become permissive behaviors and tolerated, given their private character which does not come into open conflict with moral, medical or legal requirements. Moreover, in a functionalist conception, such acts, are considered to have a beneficial character for the society, given that they fulfill numerous social functions with a "sublimation" character. The „normal” sexual deviance is, from this point of view, a kind of "neutral deviance" that does not affect either society or individuals, having the ability to orient biological impulses to socially desirable paths.

The pathological sexual deviance takes into account those cases where there is a high correspondence between the social norms, the legal prescriptions and the behaviors of the individuals. Following the predominantly individual character of this form of deviance, its labeling is based, rather, on the invocation of medical criteria rather than social or cultural norms. For example: rape, incest and pedophilia acts.

Group sexual deviance occurs when the sexual behaviors of individuals are associated with the norms and values of distinct subcultures, which is why it is also called ",subcultur$\mathrm{al}^{\prime \prime}$ deviance. These subcultures are characterized by a double status: on the one hand, they are stigmatized and marginalized in relation to the domination of the legitimate sexual culture, on the other hand, within their individuals they acquire security and their full identity. The most relevant examples of subcultural deviance are mentioned, prostitution and homosexuality, which imply different or alternative forms of organization, behavior, norms and values compared to those of "legitimate" forms of sexuality.
According to the secretive, immoral and criminal nature of most sexually deviant behaviors, the actual extent and prevalence of this phenomenon is really unknown. Among the most common paraphilic acts commited by sex offenders are child molestation, rape, exhibitionism and voyeurism (Abel et al., 1987).

The deviant sexual phenomena have to be present over a period of at least six months in order to meet criteria for one of the following nine paraphilic categories: exhibitionism; pedophilia; fetishism; frotteurism; sexual masochism; sexual sadism, transvestic fetishism and voyeurism (Saleh and Berlin, 2008).

John Money (1984) identified over 32 different and distinct paraphilias. Based on the phenomenological feature, he defined six subtypes of paraphialias, such as: the sacrificial; the predatory; the mercantile; the fetish; the eligibility and the allurement.

\section{Sexual sadism: definition, etiology, assesment and treatment}

Sexual sadism is a extracting sexual pleasure from causing pain to another living being. Fromm (1977), describe sadism as the drive to have absolut control over another person or animal. Sadism is commonly seen in individuals with additional paraphilias. The study from Abel et al., (1988), found that 18\% of their sample of sex offender sadists were also masochistic, $46 \%$ had raped, $21 \%$ had exposed themselves, $25 \%$ are engaged in voyeurism, $25 \%$ had engaged in frotteurism and $33 \%$ are engaged in pedophilia. The collected data on 30 sexual sadists by the FBI show their most interesting findings that include a percent of their sample with a history of $43 \%$ of homosexuality, more than $50 \%$ had no prior criminal record and $50 \%$ had a history of drug abuse after alcoholism (Dietz, Hazelwood and Warren, 1990). Dietz and his colleagues also found these men to be profoundly narcissistic. Although some sadists appear to stay within the realm of consensual sadomasochistic activities with a masochistic partner (Hucker, 1990), others seem to thrive on inflicting pain on a non-consenting person. 


\section{Etiology}

Report data show a number of $75 \%$ sadistic males declarations that they have been aware of their deviant interests prior to adulthood (Breslow, Evans and Langley, 1985; Spengler, 1977). On the other side, according to Scott (1983), sadistic females tend to become involved in the behaviors through adult relationships with masochistic men, discovering pleasure in sadism through its practice.

In the literature there are three theories regarding sexual sadism, namely: psychoanalytic, behavioral and biological theories.

In the psychoanalytic theory, Freud (1961) affirms that sadism originates when a child misinterprets sex as a painful by observing his parents having sexual relations.

Behavioral theory is about: conditioned sexual arousal followed by masturbation and sexual fantasies that are reinforced encapsulates behaviorist thought on the basic origins of sadistic behavior (McGuire, Carlisle and Young, 1965).

Biological theory: It has been hypothesized that neurological abnormalities may be responsible for sexual sadism. Several studies have found mild associations between sadism and temporal lobe abnormalities (Graber et al., 1982; Hucker et al., 1988; Gratzer and Bradford, 1995). It seems possible that these abnormalities could also be the result of physiologically and psychologically painful sex or an unidentified third variable. Other studies have examined hormonal differences between sexual sadists and controls without finding any significant differences (Bain et al., 1987).

\section{Assesment}

According to Holmes and Holmes (1994) to understand what elicit and maintain sexual sadism involves assessing four major areas. These four areas include having fantasies about inflicting pain, being attached to an inanimate object or part of the body, engaging in ritualism that focused on the suffering of others and they feel a compulsion to act out sadistic fantasies. Some of this information may be gathered through the self-report of the psychological testing and the perpetrator, while plethysmography and using of the records reviews, particularly accounts of the crimes provides a useful data (Sbraga, 2003).

Psychological tests that may have investigative or treatment utility with sexual sadists are those that include both sexual and aggressive factors. This instruments: Sexual aggression scale (ASA) (Malamuth, 1989) and the Multidimensional assessment of sex and aggression (MASA) (Knight, Prentky and Cerce, 1994) have the strongest psychometric properties. The ASA was designed to measure the appeal of sexual aggression. All scales have an internal consistency ranging from .78 to .92 with high test-retest reliability. The MASA was designed to measure aggressive and sexual fantasies, cognitions, and behaviors. The internal consistency is in the acceptable range, with all scales at least .60 and 89 percent of them higher than 80 . Test-retest reliability is also acceptable (Sbraga, 2003).

Fedora, et al., (1992) found a distinctive phallometric profile for sexual sadists. Sexual sadists in their study became sexually aroused to slides of nonsexual violence against fully clothed women, unlike comparison participants. In addition to finding a distinct pattern of responding that corresponds to physical violence against women, a separate sadistic profile demonstrates deviant arousal to the domination and humiliation of women (Thornton, 1993; Sbraga, 2003).

\section{Treatment}

Treatment objective for sexual sadists include controlling deviant sexual arousal, increasing victim empathy, modifying cognitive distortions, and increasing social competency and balance in the lifestyle (Sbraga, 2003).

Techniques for modifying deviant sexual arousal include electroshock, olfactory aversion, covert sensitization, vicarious sensitization, masturbatory satiation and reconditioning, and chemical castration (Sbraga, 2003).

Victim empathy training includes elements such as: meeting with victims of sexual aggression, hearing audiotaped 911 calls from frantic victims, watching videos of victims describing their experiences, writing unsent letters to vic- 
tims, and discussing personal victimization experiences while relating one's experience to the experience of other victims (Sbraga, 2003).

Changing cognitive distortions involves the identification of distorted thinking and issuing challenges to those thoughts, typically in a group therapy format. Increasing social competency may mean different skills, training for different offenders based on individual deficits. Some offenders may be inept in general communication. Others may have problems with assertiveness, intimacy, or anger (Sbraga, 2003).

Lifestyle balance also implies different needs for different offenders. Some offenders have problems with substance abuse, and others do not. Others may need treatment for other types of unbalanced behavior that establishes or maintains their deviance, such as viewing pornography, gambling, or isolating themselves from others. Established adjunctive treatments may be necessary to meet the unique needs posed by a particular presentation of sexually deviant behavior (Sbraga, 2003).

\section{CONCLUSION}

Sexual deviations are defined as sexual behavior disorders that can take many forms. These disorders are classified into three groups: deviations regarding the partner's choice, disorders related to a seduction behavior and the sexual act itself. People with deviant sexual behavior usually use sex to get rid of other problems, such as loneliness, depression, anxiety or stress. They can continue to engage in risky sexual behaviors, despite the fact that serious consequences can occur, such as health problems, sexually transmitted diseases or loss of relationship. Affected persons require medication or psychological treatment, especially when sexual disturbances harm others, such as pedophilia, sexual sadism.

Funding Sources: This research did not receive any specific grant from funding agencies in the public, commercial, or not-forprofit sectors.

\section{REFERENCES}

1. Abel, G. G., Becker, J. B., CunninghamRathner, J., Mittelman, M., \& Rouleau, J. L., 1988. Multiple paraphilic diagnoses among sex offenders. Bulletin of the American Academy of Psychiatry and the Law, 16, 153-168.

2. Abel, G. G., Becker, J. B., Mittelman, M., Cunningham-Rathner, J., Rouleau, J. L., \& Murphy, W. D.,1987. Self-reported sex crimes of nonincarcerated paraphiliacs. Journal of Interpersonal Violence, 2, 3-25.

3. Bain, J., Langevin, R., Dickey, R., \& Ben-Aron, M., 1987. Sex hormones in murderers and assaulters. Behavioral Sciences and the Law, 5, 95-101.

4. Breslow, N., Evans, N., \& Langley, J., 1985. On the prevalence and roles of females in sadomasochistic sub-culture: Report of an empirical study. Archives of Sexual Medicine, 14, 303-317.

5. Dietz, P., Hazelwood, R. R., \& Warren, J., 1990. The sexually sadistic criminal and his offenses. Bulletin of the American Academy of Psychiatry and the Law, 18, 163-178.

6. Fedora, O., Reddon, J. R., Morrison, J. W., Fedora, S. K., Pascoe, H., \& Yeudall, C. T., 1992. Sadism and other paraphilias in normal controls and aggressive and nonaggressive sex offenders. Archives of Sexual Behavior, 21, 1-15.

7. Freud, S., 1961. On sexuality. Markham, ON: Penguin.

8. Fromm, E., 1977. The anatomy of human destructiveness. Markham, ON: Penguin.

9. Graber, B., Hartmann, K., Coffman, J., Huey, C., \& Golden, C., 1982. Brain damage among mentally disordered sex offenders. Journal of Forensic Sciences, 27, 127-134.

10. Gratzer, T., \& Bradford, J., 1995. Offender and offense characteristics of sexual sadists: A comparative study. Journal of Forensic Sciences, 40, 450-455.

11. Holmes, R. M., \& Holmes, S. T., 1994. Murder in America. Thousand Oaks, CA: Sage.

12. Hucker, S. J., 1990. Necrophilia and other unusual paraphilias. In R. Bluglass \& P. Bowden (Eds.), Principles and practice of forensic psychiatry (pp. 723-728). London: Churchill Livingstone.

13. Hucker, S. J., Langevin, R., Wortzman, G., Dickey, R., Bain, J., Jandy, L., et al., 1988. Cerebral damage and dysfunction in sexually aggressive men. Annals of Sex Research, 1, 33-47. 
14. Knight, R., Prentky, R. A., \& Cerce, D. D., 1994. The development, reliability, and validity of an inventory for the multidimensional assessment of sex and aggression. Criminal Justice and Behavior, 21, 72-94.

15. Laws, D. R., \& O'Donohue, W., 1997. Fundamental issues in sexual deviance. In D. R. Laws \& W. O'Donohue (Eds.), Sexual deviance: Theory, assessment, and treatment (pp. 1-21). New York: Guilford Press.

16. Malamuth, N. M., 1989. The attraction to sexual aggression: Part One. Journal of Sex Research, 26, 26-49.

17. McGuire, R. J., Carlisle, J. M., \& Young, B. G., 1965. Sexual deviation as a conditioned behavior: A hypothesis. Behavior Research and Therapy, 2, 185-190.

18. Money, J., 1984, Paraphilias: Phenomenology and classification, American Journal of Psychotherapy, 38(2), 164-179.
19. Paulauskas, R., 2013. Is causal attribution of sexual deviance the source of thinking errors? International Education Studies, Vol. 6(4).

20. Saleh, F.M. \& Berlin, F.S., 2008. Sexual deviancy: diagnostic and neurobiological considerations, Journal of Child Sexual Abuse, 12:3-4, 53-76.

21. Sbraga, T. P., 2003. Sexual deviance and forensic psychology: a primer, Handbook of Rorensic Psychology, 429-470.

22. Scott, G. G., 1983. Dominant women, submissive men. New York: Praeger.

23. Simon, W. and J. Gagnon, 1967. 'Homosexuality: The Formulation of a Sociological Perspective', Journal of Health and Social Behavior 8(3): 177-85.

24. Spengler, A., 1977. Manifest sadomasochism of males: Results of an empirical study. Archives of Sexual Behavior, 6, 441-456.

25. Thornton, D., 1993. Sexual deviancy. Current Opinion in Psychiatry, 6, 786-789. 